\title{
A intricada leitura de literatura - um novo processo socioeducacional de conhecimento
}

\section{The intricate reading of literature - a new social and educational process of knowledge}

\author{
Robson Coelho Tinoco ${ }^{1}$
}

\begin{abstract}
RESUMO
Frente aos desafios educacionais neoliberais pós-modernos, à escola brasileira - e à prática / ensino de leitura também literária - cumpre-se o objetivo de reconstruir o novo sobre as marcas de uma relação pedagógica professor-aluno rotineiramente desgastada. Nesse ambiente, surgem questões como o que se pretende lendo aleatoriamente textos na escola? Para onde leva essa leitura? Quem somos, quando se lê? Por que nos transformamos nessas cibermáquinas de passividade metodológica? Nossos alunos estão sendo orientados, previamente, a leituras de determinados autores canônicos, e não canônicos, sabendo o motivo de tal leitura aplicada a sua realidade de leitor? E "ler" literatura é algo que se ensine? Pode-se ensinar alguém a ler entendendo a leitura como fonte dupla de informação e prazer? Não há mais como imaginar uma escola periférica, às margens dos acontecimentos diários e, assim, ou essa nossa nova escola - professores, alunos, agentes administrativos - se adapta produtivamente a essa realidade contemporânea ou estará fadada a perder o rumo da história nacional, regional e mundial. Adaptação produtiva, no sentido de renovar a crítica aos costumes, aos valores, aos preconceitos. Os dados que complementam tais questões teóricas resultam de pesquisa desenvolvida com alunos do ensino médio, de uma escola pública de São Paulo-Brasil, com o objetivo de avaliar, em sala de aula, práticas de uma leitura produtiva com foco no papel do que aqui se considera como leitor-real.
\end{abstract}

Palavras-chave: educação; leitura; literatura; sociedade.

DOI: $10.1590 / 0104-4060.36287$

1 Universidade de Brasília. Instituto de Letras. Departamento de Teoria Literária e Literaturas. Brasília, Distrito Federal, Brasil - Campus Universitário Darcy Ribeiro - Asa Norte. CEP 70910-900. 


\begin{abstract}
Against postmodern neoliberal educational challenges, the Brazilian school - and practice / teaching reading including literary reading -, one meets the objective of reconstructing the new features of a pedagogical teacher-student relationship that is routinely worn. In this environment, questions arise as what is the aim of randomly reading texts in school? Where does this reading leads to? Who are we and when we read? Why did we become such cybermachines of methodological passivity? Our students are being told in advance to read the canonical, and non-canonical authors, knowing the reason for such reading applied to their reality as readers? And "reading" literature is something you can teach? Can you teach someone to read understanding reading as a double source of information and pleasure? There is no way to imagine a peripheral school, on the banks of the daily events and thus, our new school - teachers, students, administrative staff - adapt themselves productively to this contemporary reality or they are doomed to lose the track of national, regional and world history. That is a productive adaptation to renew criticism of customs, values, prejudices. The data that supplemented such theoretical issues stem from a research conducted with students of middle school, in a public school in Sao Paulo-Brazil, with the objective of evaluating, in the classroom, practices of productive reading focusing on the role of which is considered as a real-reader.
\end{abstract}

Keywords: education; reading; literature; society.

[...] O tempo contemporâneo é, como já observavam Leopardi e Hegel - ainda que com filosofias opostas -, hostis à literatura, que só se tolera como atividade ilhada, abstraída da prática social corrente e, daí, reificada ou monologizada (BAKHTIN, 2003).

No desejo de aprimorar o ensino, de maneira geral, é necessário conceber um sentido mais efetivo de aprendizagem, fundado no desenvolvimento de habilidades críticas. Nesse âmbito, é essencial que se aprimorem a capacidade de as pessoas (alunos, professores) resolverem novos problemas - e que a escola reaprenda sua fabulosa função de como ensinar a aprender. Ainda, nesse aprimoramento, deve-se estabelecer um eficaz processo de (re)interpretação das informações acessadas, processo em que o homem, mais e mais, se vê substituído - em várias funções e ações - pela máquina. Por isso, aprender a aprender é mais um dos elementos essenciais dessa nova equação educacional que se nos mostra frente a tanta "funcionalidade" política, econômica e mesmo religiosa. 
No campo da educação, mais especificamente, tal notada hostilidade se escora, a sua maneira, em novíssimas manifestações textuais como as estruturadas pelos hipertextos que pululam, aos milhares e a cada dia, nas páginas da internet. Esses, aliás, se apresentam como a próxima etapa revolucionária, como a substituição de cinco séculos de cultura impressa. Em sua última versão para a internet, pode bem significar uma extensão da televisão e de outros meios visuais, logo que esses meios de comunicação sejam reconfigurados como formas hipertextuais suplementares. Muito embora "as celebrações de seu potencial revolucionário sejam hoje rotineiras, como diz Glenn Jones, citado por Anson, por exemplo, o hipertexto é nada mais nada menos do que o processo de renovação da própria civilização" (MIALL, 2010, p. 8).

Assim, importante é não baixar a guarda ante os desafios educacionais neoliberais pós-modernos porque os inimigos, à espreita, esperam a primeira demonstração de cansaço, desestímulo, desorientação (SILVA, 2002). Nesse embate subjetivo, nunca tanto como hoje envolvendo a escola brasileira, e nela a prática / ensino de leitura também literária, cumpre-se o objetivo de reconstruir o novo sobre os escombros cibernetizados de uma relação pedagógica professor-aluno rotineiramente desgastada. Relação em que o aluno não ouve a mensagem do professor, não acredita em sua versão de humanidade, de poesia, de vida; em que o aluno sai de uma aula sobre leitura de textos líricos nacionais e se porta como um porta-estandarte multifacetado de modas e trejeitos culturais pretensamente globalizados.

São muitos os casos tragicômicos que sintomatizam boa parte de nossa situação escolar atual, espremida entre teorias burocratizantes e métodos aplicados sem a devida consideração de sua eficácia e pertinência. Casos que sintomatizam uma condição de ensino em que professores e alunos, senão mesmo como inimigos, se veem como desconhecidos, transeuntes inversos de uma imensa avenida informacional traçada sem começo nem fim determinados - avenida imersa nessa contemporânea sociedade líquida (BAUMAN, 2009). Avenida repleta de outdoors coloridos e brilhantes oferecendo desde adolescentes, com corpinhos adultizados em passarelas hiperfashion, até facilidades impensáveis de cópias de trabalhos via internet. Resistir é quase impossível e resistir para quê? E resistir como? São as tentativas de respostas, pelo menos, a perguntas desse tipo que nossa escola precisa integrar ao ensino de leitura de literatura aliado, é evidente, a todas as outras suas atividades.

Não há mais como imaginar uma escola periférica, às margens dos acontecimentos diários colados neste jorro informacional disformemente globalizado que inunda nossos ouvidos e olhos, desejos e valores. Inundação informativa que avança em todos os níveis, já que até a universidade não pode mais se considerar tipo ideal de espaço construtivo em que teoria e prática interagem 
sob uma óptica social integracionista. Ou essa nossa nova escola - professores, alunos, agentes administrativos - se adapta produtivamente a esta realidade contemporânea ou estará fadada a perder o rumo da história nacional, regional e mundial. Adaptação produtiva, no sentido de renovar a crítica aos costumes, aos valores, aos preconceitos; no sentido de redirecionar o olhar do aluno à função cultural da leitura como veículo de conscientização social e fonte de prazer estético - sentidos de ética e estética, na escola, precisam reencontrar seus espaços privilegiados, revelados por metodologias exigentes, além de só repetitivamente originais (lembrem-se das propostas de os alunos fazerem letras ao ritmo do rap ou hip hop, tão ao seu gosto provinciano...).

Considerando o novo contexto desses ambientes educacionais, estudos de grupos envolvidos com novos usos de uma tecnologia cada vez mais presente e necessária avaliam que, e mesmo tão avançada em termos de elementos computacionais, ela ainda não pode ser amplamente utilizada pelas escolas marcadas por estruturas de ensino ainda muito dependentes de um sistema de aprendizagem focadamente presencial e didático-sequencial. Essa realidade não facilita a popularização de seu uso (dos elementos da informática) pelos professores e mesmo contribui, em alguns casos, para o aumento de certo tipo de "tecnofobia" (CARRERA, 1998). Na verdade, sob um ponto de vista pragmático, a verdadeira revolução das redes telemáticas está por acontecer, já que os sistemas de utilização dessa "onda tecnológica" carecem, ainda, de uma pedagogia, uma didática e, sobretudo, de uma apropriação artística e emocional das redes para integrá-las na formação dos docentes e na aprendizagem dos alunos (PISCITELI, apud CARRERA, 1998).

Ainda se fazem pouco presente nas pautas de discussões acadêmicas, por exemplo, itens como estratégias eficazes, avaliadas pragmaticamente, para diminuir a "distância" da qualidade de ensino em escolas públicas e privadas. Há pouco espaço, efetivamente, para uma pauta de discussões sobre a realidade nacional como a do triângulo da seca, no nordeste brasileiro, ou a do um milhão e seiscentos mil desempregados da região da Grande São Paulo, ou a média de tempo de escolarização do brasileiro (de 6,7 anos, para o branco; 4,7 anos para o negro ${ }^{2}$ ), questões que poderiam ser melhor equacionadas com vontade $\mathrm{e}$ ação política conjunta entre os vários órgãos educacionais e instituições sociais.

Pouco ainda se avalia sobre o fato de que crianças das mais variadas regiões do mundo (leve-se em conta o tamanho continental de um país como o Brasil, com tantas diferenças regionais) poderiam ter igual acesso, entre outras possibilidades, a bibliotecas com bons e interessantes livros, revistas e jornais ou

2 Estudo, de 2004, apresentado pelo Programa das Nações Unidas para o Desenvolvimento (Pnud), após análise de 120 indicadores socioeconômicos, com recorte racial. 
acesso a computadores, instalados nas escolas, conectados à internet - transformando alunos, de um subúrbio qualquer, em internautas conectados aos quatro cantos "civilizados" do mundo ocidental e oriental $l^{3}$. Mas para o sucesso de quaisquer dessas tentativas faz-se necessário um amplo trabalho articulado entre organizações particulares e instituições públicas visando à transformação efetiva dos projetos de vida das crianças e dos jovens, via formação socioeducacional.

Quanto à questão de conceitos e modelos de atuação das organizações e instituições, a professora Marilena Chauí, do Departamento de Filosofia da Universidade de São Paulo, considera sua relação, ao avaliar que aquelas se estruturam por meio de práticas socioeconômicas fundadas na instrumentalidade de seus objetivos - planejamento, gestão, previsão de investimentos, controle, êxito etc. (CHAUÍ, 1999). As organizações particulares, assim, e sempre com o intuito de auxiliar, preocupam-se mais em absorver, via de regra, a pouca capacidade de locação e uso de recursos das instituições sociais. Essas, por aspirar a uma visão do local interagindo com o social (pelas ações articuladas às ideias de causa e consequência de fatores internos e externos das pessoas em suas experiências mundo-vida), têm um componente necessariamente universalista, ao contrário das organizações, estruturadas pela busca da otimização fundada na especificidade de projetos de aplicação rápida e resultados objetivamente aferíveis.

Para que propostas inovadoras (públicas e privadas) articuladas à participação popular (grupos sociais, educacionais) tenham mínima possibilidade de sucesso para a devida conscientização de uma questão de cidadania, é fundamental a implantação de novos sistemas integrados (políticos, artísticos, educacionais etc.) gerando uma estrutura social racional. Nesse sentido, devem ser consideradas teses como a do "capital social"4 representado pela medida das relações que os indivíduos têm, as quais permitem, ou não, que se integrem a um dado contexto socioeconômico. Essa integração faz com que se perceba, evitando tanto quanto possível, a manifestação da marginalidade em seus mais variados níveis. Ela é medida pela força - melhor dizendo, pela atuação prática e eficaz - da presença da religião, da família, da escola, dos centros de saúde, dos órgãos policiais, dos espaços e centros de lazer e informação.

3 Pouco adianta comprar computadores se não se treinam professores para os usar, se não se pagam bons salários a eles. Considere-se uma "evolução educacional" baseada em acesso às informações, atualizadas constantemente, sem limite de espaço e tempo; perguntas e respostas estabelecidas por meio do uso de correio eletrônico; a troca de informações com alunos e professores de outras escolas e universidades; a coleta de material de pesquisa para experimentos variados em laboratórios; a edição de figuras, desenhos, mapas, gráficos detalhados ou a execução de programas de maneira interativa etc.

4 Caderno Especial “Ano 2000 cidades”, Folha de São Paulo, ed. 2 de maio de 1999. 
Assim, nesse caudal de ações no geral desconectadas, de pedra em pedra os caminhos metodológicos (também educacionais) vão se fazendo rumo aos desencontros da pós-modernidade com seu novo-sentido de de-vir pela fragmentação. Fragmentação excêntrica: o que não é meu não me pertence, portanto, renego o que não me pertence. Meu vizinho se resume, inconcluso, a um número cardinal silencioso, uma sombra amorfa, um irritante barulho no teto ou ao lado; meu personagem preferido é uma mancha no texto - espectro do vazio lacunar de Iser - que não entendo porque não compreendo sua função em minha vida de encontros remarcados entre videoclipes musicais, teclas de delete e senhas bancárias. Sentido da fragmentação educacional contemporânea: ou a escola muda, ou a mudança diária da vida passará por cima dela, feito um livro sem palavras para um leitor cego, mas obcecado pelo novo.

"Gostar de viver". Com esta frase, Paulo Freire resumiu sua resposta ao pedido de duas professoras que o encontraram em uma festa, em Nova York. Elas pediam que lhes dissesse como ser um bom professor, apesar das dificuldades todas. Gostar de viver e de ler o novo, ainda que assentado no que já se leu - característica do texto literário de qualidade: ser renovado segredo infindável. Gostar da vida, enfim, como possibilidade real, planejada dia a dia e mirando o futuro, de realização de projetos dialógicos bakhtinianos de inserção social entre leituras frutíferas. Projetos que incluem a sociedade letrada e iletrada numa efetiva reformulação de processos educacionais empreendidos com determinação, desnecessidade de autopromoção, processos empreendidos com humildade ativa entre atitudes práticas, aplicadas. Fora disso, quase tudo já foi feito e não deu certo.

Nesse sentido, ler com eficiência é, voluntariamente, afastar-se do mundo real - oferecido entre apelos de consumo e egolatrias hipercompetitivas -, desapegando-se de exigências da pressa pelo número de páginas, da quantidade informacional pelo conhecimento qualitativo. Ler é, ainda que solitariamente mas olhando para cima, como dizia Barthes, estabelecer passeios de volta ao sempre-desconhecido, imposto por essas avalanches diárias derramando informação ininterrupta pela tv, internet, bocas, cartazes, filmes, revistas, jornais. Ler é, apreendendo todos esses mundos de falas, cores, imagens e olhares, perceber a importância de uma opção - voluntária, solitária - em assumir o exigente prazer de querer saber mais. Ler é se afastar dos outros para se encontrar, por meio de si, nesses outros; ler é retornar para eles. Assim, ler pelos livros, pelos tablets, pelos e-books; assim, ler as palavras onde elas estiverem cravadas, gravadas, grafadas. Assim ler o mundo que está por aí, o tempo todo, a nos espiar canibalmente, querendo sufocar nosso sentido de antropofagia oswaldiana. 


\section{A reconstrução de um leitor real, antes de ideal}

Ao compor suas conferências com o título de Seis passeios pelo bosque da fição, Umberto Eco avalia, dentre outros elementos textual-narrativos, o que chama de a figura do "leitor-modelo", para quem, virtualmente, todo autor escreveria. Nele, há o leitor que assume uma posição essencial como figura de compreensão textual - leitor-análise -, determinada como a "terceira via", para os teóricos da Estética da Recepção. Nele, vive o leitor que, com "a morte do texto" pelo viés pós-estruturalista de Barthes, é empossado como mais um dos personagens dos textos - o leitor-personagem. Sem abdicar de todas essas teorias, valorosas ao seu momento mas conscientemente ou não tendenciosas, como fundamento de análise, o que aqui se propõe é a reconstrução do leitor-real (TINOCO, 2010).

Leitor-real que se manifesta como representação das leituras de mundo resultantes da percepção de que as informações estão, mesmo, articuladas em determinados níveis de compreensão. Essas leituras de variados "textos" (imagens, símbolos, produção escrita, sons etc.) representam a articulação do tecido de informações para quem, cansado de tanta mesmice ciberneticamente acadêmica e midiática, deseja se conhecer na medida em que percebe o mundo que o rodeia, desnudando-o criticamente.

Tal desnudamento é construído na opção pelo fato de que pouco adianta, no geral - dada a atual conjuntura sociopolítica brasileira/latino-americana -, propor metodologias mirabolantes de leitura. Com essas metodologias, seria possível que leitores, desavisados das dificuldades e necessidades de uma leitura produtiva, pudessem ser leitores eficientes de, por exemplo, obras literárias. Por essas obras, deve-se imaginar que é possível uma análise, minimamente reveladora de elementos novos, sem a devida articulação ao que há de informação hoje em dia, também como exemplo, comunicada via on-line pelos ships e bytes de toda uma teia informacional tratando de tudo sobre tudo, o tempo todo. Nesse caudal de informação regurgitada sem fim, destaca-se, como ícone representacional dessa mudança de época em que estamos encravados - seres duplos -, a propaganda-chave do canal Globonews: NUNCA DESLIGA.

Uma questão: como desenvolver em leituras de mundo interessantes e atuais, incluam-se aí as literárias, com professores desmotivados ou ainda muito dependentes de metodologias ultrapassadas, tentando explicar só assuntos periféricos a pontos centrais de textos literários: É possivel mesmo, 100 anos de pura solidão? Romance é romance porque é romântico? A pedra do poema de Drummond era pedra mesmo? O sucesso de Paulo Coelho se deve à quali- 
dade literária, guiada por seus anjos, bruxas e duendes? ${ }^{5}$ Não obstante essas "questões literárias", Mikhail Bakhtin (2003) avalia que, sendo a literatura um fenômeno complexo e a pesquisa literária uma ciência ainda jovem, não se pode valorizar uma metodologia qualquer como tipo de remédio milagroso. A diversidade dos procedimentos é justificada, até mesmo indispensável, contanto que tais procedimentos deem provas de seriedade e descubram novos aspectos no fenômeno literário.

Assim, no "trabalho" com literatura o que se tem, como parte ainda expressiva de uma realidade educacional que praticamente abrange todo o Brasil, são professores despreparados porque submetidos à realidade de uma situação objetiva que os torna meros empregados público e/ou privados. Nessa rotina, correm de escola em escola (ou mesmo de faculdade em faculdade, universidade em universidade) a fim de garantir um salário mensal compatível com seus anos de estudo e, quando é o caso, produção científica. São despreparados porque, em nome dessa disforme correria, olham, extenuados, a pluripotente sociedade pós-cibernética ${ }^{6}$, a avant-guarde mercantilista, pragmaticamente envolvente $\mathrm{e}$ cativantemente elitista.

Nesse contexto, o leitor-real procura reagir, ainda como figura marginal, frente a uma poderosa realidade digital em que se vende de autoajuda a bulas para montagem de bombas caseiras, realidade que defende a tentativa idealizante de que para se ler bem basta um bom livro e um bom professor-orientador. Imersas nessa realidade, ouvem-se defesas para que se deixem os alunos ler o que bem entenderem; para que se façam leituras para se produzir, depois, as tais fichas de leitura; para que se leiam as obras canônicas pelos livros-resumos à disposição em bancas de revistas e até bibliotecas. No ensino superior, ficam obrigados os alunos (adultos agora) a ler os livros que a escola exige e que não foram devidamente lidos (pesquisas dão conta que por volta de $30 \%$ do que se estuda no ensino fundamental e médio não têm praticamente nenhuma aplicação na vida diária das pessoas). Outra questão imersa nessa realidade: por que ler Machado de Assis, Gabriel Garcia Marquez, Drummond, ou Paulo Coelho, sem o leitor estar percebendo o objetivo real disso?

5 Quanto a este autor, aliás, há uma ideia-imagem peculiar, devida ao poeta e professor Afonso Romano de Sant'Anna: "Dos três mistérios atribuídos a Nossa Senhora de Fátima, o sucesso de Paulo Coelho pode ser considerado o quarto".

6 A expressão “cibernética” foi usada já em 1943, em artigo escrito por Arturo Rosenblueth, Norbert Wiener e Julian Bigelow. 


\section{Plano de conscientização: ler a palavra carregada de mundo}

Esse aqui citado processo conscientizador se revela em um determinado plano levando em conta a condição primeira de, pela reflexão e questionamento, libertar-se de tudo que se mostra, a princípio, politicamente correto, filosoficamente reacionário, psicologicamente simples. Esses três níveis teóricos surgem como componentes de uma estrutura social tradicional e ultrapassada, porque fechada em si mesma - estrutura que tem na própria preservação inquestionável o único, e por isso injusto, sentido de funcionamento e continuidade.

Tal processo conscientizador expõe variantes, e uma das mais revolucionárias e criticadas, e ainda mal trabalhadas, é a leitura desenvolvida por um leitor-real. Nesse processo, pois, é essencial estar consciente de que ler é mais que ver, já é ler melhor e essa consciência é trazida à luz por uma leitura crítica, revelando e refletindo uma função social da pessoa. Essa função implica um funcionamento mais integrado entre os vários níveis de comunicação, que vão desde as primeiras informações no convívio familiar, passa pela relação escola-pessoa e se reflete no dia a dia profissional que, se tudo é mesmo um processo cíclico, finda por manifestar-se de novo na família.

Conscientizada num processo de desenvolvimento intelectual pelas experiências vividas, uma pessoa pode, quando da fase de sua vida escolar, e enquanto leitor, realizar uma leitura mais produtiva no que diz respeito à apreensão das informações subjetivas - suportes das chamadas informações essenciais. A questão é que a pessoa se aprimora enquanto desenvolve sua capacidade de refletir, questionar, descobrir - aprimoramento promovido pela conscientização de um ser-agente consciente de si e do mundo que o cerca.

Por esse processo tem-se um leitor consciente que "com o aprimoramento da leitura numa percepção estética e ideológica mais aguda e com a visão crítica sobre sua atuação e a de seu grupo, torna-se agente de aprendizagem, determinando ele mesmo a continuidade do processo, num constante enriquecimento cultural e social" (AGUIAR; BORDINI, 1988, p. 91). Tem-se um leitor-agente ágil na apreensão do "texto implícito diluído" no texto apresentado pela mensagem escrita; ágil no exercício da reflexão, da descoberta, da análise comparativa e na relação entre informações relevantes ou não para a compreensão de uma dada obra literária.

Uma leitura produtiva busca "contato" com uma pessoa, representada por sua expressão de leitor que percebe, também por esse exercício (só o ato consciente de ler não possibilita uma real apreensão do momento sociocultural que se vive), uma ampliação de suas capacidades, já que "o processo de recepção se 
inicia antes do contato do leitor com o texto. O leitor possui um horizonte que o limita mas pode transformar-se continuamente, abrindo-se. Este horizonte é o do mundo de sua vida, com tudo que o povoa: vivências pessoais, culturais, normas jurídicas, filosóficas etc.” (AGUIAR; BORDINI, 1988, p. 87).

Uma boa - e produtiva - leitura é ler o mundo em uma obra e para essa leitura produtiva é fundamental avaliar a obra como linguagem que mostra o mundo, porque o revela na medida em que o leitor se percebe refletido e condensado nela. Tem-se, enfim, como uma das consequências desse processo comunicativo, um leitor que lê melhor, porque lê mais, apreendendo mais conscientemente as informações, pelo fato de ter aprimorado sua leitura. Como concretização desses conceitos em sala de aula, segue esquema (de um bimestre letivo) para leituras produtivas e leitores-reais. Esta proposta foi aplicada no período de setembro a outubro de $1998^{7}$, para 70 alunos do ensino médio da Escola Estadual Comendador Rodrigues Alves, de Guaratinguetá/SP:

$1^{\circ}$ MÊS (set/98) - Aulas (objetivos programados)

$1{ }^{a}$ Semana... $\quad 1$. Comentários gerais sobre as atividades a serem realizadas - informações referentes ao conceito do papel e função do leitor-real.

2. Distribuição de temas (vários, relacionados à conscientização sociocultural) para pesquisa posterior.

3. Discussão proposta: "Níveis de importância de textos escritos".

$2^{\mathrm{a}}$ Semana... 4. Leitura de três textos (diferentes níveis de construção e compreensão).

5. Leitura de um texto técnico e um poético (mesmo assunto). dissertativo).

6. Produção de um breve texto (p. ex., um parágrafo $3^{\mathrm{a}}$ Semana... $\quad$ 7. $1^{\circ}$ trabalho c/ obras literárias: informações e divisão de grupos para posterior pesquisa.

8. Apresentação de Temas (vide aula 2).

9. Continuação da aula anterior (uso de meios audiovisuais etc.).

$4^{a}$ Semana... 10. Continuação da aula anterior (uso de meios audiovisuais etc.).

7 Como base de meu Mestrado em Língua Portuguesa, na Pontifícia Universidade Católica de São Paulo (PUC-SP). 
11. Leitura de texto proposto para análise ( $1^{\mathrm{a}}$ experiência de leitura produtiva).

12. Continuação da aula anterior.

$2^{\circ} \mathrm{MÊS}-($ out $/ 98)$

$1^{\text {a }}$ Semana... 13. Apresentação das pesquisas feitas (distribuídas para os grupos à aula 7).

14 e 15. Continuação da aula anterior (utilização de vídeos, curtas-metragens etc.).

$2^{a}$ Semana... 16 e 17. Continuação das aulas anteriores.

18. Avaliação geral, sob supervisão do professor, das pesquisas realizadas.

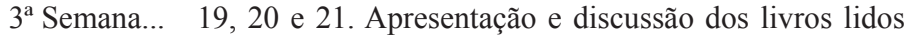
(distribuídos na aula 7).

4 ${ }^{\mathrm{a}}$ Semana... 22 e 23. Continuação das aulas anteriores.

24. Avaliação final das atividades / Tema proposto:

Um aluno mais consciente e sua produção escolar - processo e produto.

Os objetivos da proposta eram: 1. Traçar um quadro representativo do envolvimento dos alunos com a questão do "ato de ler"; 2. Analisar quanto deste ato é, conscientemente, transformado em hábito; 3 . Avaliar o processo de conscientização do aluno, promovido pelo hábito da leitura produtiva e 4 . Levantar dados para uma reavaliação dos métodos de aplicação de leitura com o objetivo de, mediante as informações colhidas, estabelecer uma proposta (como a acima) que trabalhe mais concreta e conscientemente a pessoa-aluno (leitor em potencial // leitor-real), tornando-a mais efetivamente participante do processo de "perceber melhor" o que lê.

Da metodologia desenvolvida na pesquisa - em que a proposta era um de seus elementos -, e a título de ilustrar a análise aqui feita, entre outros dados significativos, verificou-se que $85,7 \%$ dos alunos não conseguem "enxergar" a escola como um elemento indispensável na construção de uma sociedade mais justa e promotora de bem-estar geral, entendendo eles que isso cabe, fundamentalmente, ao governo. $57,8 \%$ apresentaram suas ideias sem maiores embasamentos teóricos, de qualquer ordem, ou sem estabelecer uma relação entre os conceitos socioculturais da sociedade como algo em contínua evolução e que se adaptam a determinadas circunstâncias históricas. Todavia, nesse quadro, $73 \%$ dos alunos apreenderam a proposta geral de leitura produtiva e 
$68 \%$ deles afirmaram se sentir "melhor instrumentalizados" para uma devida percepção consciente das informações - em seus vários níveis - presentes nas obras lidas (trama narrativa, perfil psicológico de personagens, pontos narrativos de clímax etc.).

Do conjunto de dados e resultados obtidos, destaca-se que a escola precisa ser um conglomerado moderno de ideias transformadoras composto não só por uma ou outra estratégia desenvolvida mais ou menos conscientemente pelo professor. São estratégias articuladas entre si - promovidas por professores e alunos integrados num processo eficaz de ações e posições modernas - que possibilitarão o (re)surgimento da escola como instituição informadora e transformadora de conceitos; instituição criativa e atuante, voltada ao projeto de promover aquisição de conhecimentos aliados a um desenvolvimento social mais justo e pleno. São assim, estratégias reais de conscientização (também quanto à leitura feita), aplicadas como metodologia eficaz de ensino e desatreladas de um mero utopismo etéreo entre saudosista, que podem aprimorar o senso crítico do aluno (leitor), e do professor, frente ao processo educacional e no que ele tem de influência no processo sócio-histórico que permeia o panorama cultural de sua época.

\section{A sala de aula como ambiente de produção criativa}

Ensino, conhecimento e leitura são três dos componentes básicos para qualquer intenção de aquisição de novas mensagens, novas linguagens, novas percepções de mundo e de pessoa. São três deles e é fundamental que não se omita para o leitor, seja em que situação for, que mais fundamental é sua própria noção de inserção social e satisfação pessoal com a possibilidade de se reconhecer. Mais, perceber que este reconhecimento se dá, também, por meio da leitura feita, da informação pertinente a que ele está tendo acesso, por meio de um ensino inteligente, flexível, exigente, crítico e integrado às exigências dessa pós-modernidade brasileira, com todas as suas variantes, falhas, desníveis, jogos políticos.

Em uma sala de aula desvinculada do dialogismo dinâmico da sociedade - sala sem sentido de local ideal para aquisição de conhecimento -, Bakhtin considera que semelhante procedimento, de desvinculamento leitor-leitura, barra o acesso à profundidade das grandes obras literárias que, nessa situação, adquirem ares de algo insignificante e frívolo, algo parado e perdido no tempo. Avalia, ainda, que não basta compreender e explicar uma obra a partir das con- 
dições de sua época e das condições que lhe proporcionou o período contíguo, o que condenaria a jamais penetrar suas profundezas de sentido. Para Bakhtin, "tudo quanto pertence somente ao presente morre junto com ele". (2003, p. 67).

Uma obra literária se revela, principalmente, por meio do sentido de diferenciação que se dá dentro da totalidade cultural da época da qual ela faz parte. Nada, todavia, permite encerrá-la nessa época, já que a plenitude de seu sentido ilimitado se revela tão somente no que ele chama de a grande temporalidade. Assim, o que se propõe como base de verificação de uma efetiva reorganização de elementos como literatura, ensino e informação-em-conhecimento é o conjunto de linhas e práticas metodológicas que cumpram o objetivo de valorizar a figura do leitor-real, dialogicamente considerado como sujeito inserido nessa grande temporalidade.

Tal conjunto serve de suporte a estudos direcionados, análises comparativas e exercícios aplicados para alunos, e mesmo não alunos, que trabalhem com leitura e produção de textos (CITELLI, 2003). Nesse trabalho é importante frisar questões do tipo aquisição crítica de informações, percepção ampliada e conscientização do leitor. Leitor visto como sujeito integrado ao momento histórico no qual seu grupo (familiar, educacional) se encontra inserido por questões sociais, educacionais, culturais e ainda outras que, devidamente articuladas, promovem o pleno sentido de convívio em sociedade.

Nesse contexto se amplia o sentido de comunicação entre sujeitos constituídos dialogicamente, e que se avaliam sob tal proposta de inter-relação constitutiva (TEZZA, 2003). Portanto, também, é necessário repensar as noções de emissor e de receptor da comunicação, que não podem mais ser considerados como pontos vazios de emissão e recepção de mensagens. Integrados, precisam ser entendidos como sujeitos dialógicos sociais plenos, com qualidades modais necessárias as suas várias competências comunicativas, além de valores oriundos das relações com o extralinguístico, devidamente inserido na contemporaneidade desta sociedade encravada no século XXI.

Ainda para Bakhtin, o importante no ato de compreensão é a noção de exotopia, de quem compreende, no tempo, no espaço, na cultura, a respeito do que se quer compreender. O mesmo não ocorre com o simples aspecto externo do homem, que este não pode ver nem pensar em sua totalidade. Em relação ao seu aspecto externo, apenas o outro pode captá-lo e compreendê-lo, devido a sua exotopia e pelo fato de ser outro. $\mathrm{O}$ encontro dialógico de duas culturas, nesse sentido, não lhes acarreta a fusão, ou a confusão; antes, cada uma delas conserva sua própria unidade e sua totalidade aberta, enriquecendo-se mutuamente.

É fundamental, também no ambiente educacional de sala de aula, sob essas macropercepções dialógicas leitura-literaturalescola-cidadania e para a mudança dos paradigmas de ação nacional-mundial, que a autoconfiança e a 
crença no outro sejam restabelecidas como parâmetros que permitam a inserção da pessoa no processo mesmo de globalização informacional. Tal processo, novamente e com ares de pós-modernidade, é anunciado como a grande via para a aldeia global - nome com que o pré-vanguardista Marshall McLuhan, algumas dezenas de anos antes, caracterizava o mundo que se interligava pelos meios de informação (mass media). A preservação dessa autoconfiança vem em auxílio de outra - renegada em nome de uma sociedade submetida ao lucro fácil e ao exagerado conforto tecnológico: a de que a fraternidade humana deve ser considerada como máximo objetivo a ser alcançado, e sempre aprimorado.

Essa deve ser a função primeira de pesquisas, teses, experimentos desenvolvidos nas universidades públicas ou não e em quaisquer entidades ou empresas empenhadas em estudar questões voltadas à melhoria da vida humana em comunidades urbanas ou rurais, à melhoria de estratégias educacionais de leitura, de produção de texto etc. É importante, aliás, a ampliação desse conceito de "comunidade", levando-se em conta todas as chamadas "novas comunidades" - envoltas por suas características peculiares - como as comunidades dos indígenas, ciganos, quilombolas, negros, palestinos, sem-teto, entre tantas outras.

Portanto, nesse novo mundo hightech - tecnologicamente marcado pela velocidade da informática e com neoposturas ecologicamente contrárias à degradação do meio ambiente - é importante uma crítica inovadoramente produtiva. Sobretudo, consideram-se os responsáveis por propostas educacionais, e aqueles que atuam como estudiosos-críticos de arte em geral e, especificamente, de literatura. Nesse quadro de reposicionamento crítico, a atuação de intelectuais e pesquisadores com sua capacidade de análise e, supõe-se, visão e intenção democráticas, nunca foi tão necessária, apesar de, em muitos casos, ser passível de reclamações variadas.

Considerados esses fatores de base, a decisão final do caminho a seguir, e por quê, é de cada um. Afora os apelos disto ou daquilo, é uma decisão absolutamente pessoal e dependente do próprio conceito de visão de mundo real de cada leitor (em potencial). É inútil, portanto, serem propostas mágicas, truques, peripécias metodológicas para ensinar o que já se sabe, mal, mas já se sabe. Na linha de uma metodologia de base sociológico-estruturalista, reforçando a ideia de Luiz Costa Lima (1979), deve-se inovar - pela dialogia sujeito x leitor, mundo $\mathrm{x}$ sala de aula - a fim de ampliar os elementos a ser considerados na leitura que se faz. Ora, se não se tira de onde não se tem, uma metodologia precisa oferecer elementos de informação para que, de posse deles, o que se propõe aqui como leitor-real possa se "redimensionar" frente a suas necessidades educacionais, a leituras de obras literárias; frente, enfim, aos seus objetivos reais de vida.

Ora, todas as práticas humanas, desde tomar de assalto a Bastilha a escovar os dentes, funcionariam por exclusão, negação e repressão (EAGLETON, 1998). 
Considere-se, ainda, que toda forma de linguagem, por exclusão, expressa uma informação. Esta, devidamente apreendida e avaliada, e negada, pode se prestar a ser um efetivo fator de aprimoramento intelectual e mesmo de convivência social. Além disso, serve de ampliação de conhecimento adquirido e, portanto, de oposição à repressão imposta.

Da metodologia desenvolvida naquela pesquisa de Mestrado e da análise ora aqui proposta, percebe-se, de fato, que cada leitor procura algo, por mínimo que seja, no texto lido. E o desconcertante é que normalmente encontra já que, de certa maneira, já traz dentro de si o que era procurado. Assim, enquanto elemento receptor de várias mensagens, esse leitor-real também foi levado a perceber que "no fluxo e refluxo de nossas paixões e afazeres, há um momento em que tudo se ajusta. Os opostos não desaparecem, mas se fundem por um instante. [...] Não é necessário ser um místico para roçar essa certeza.” (PAZ, 1996, p. 256).

\section{REFERÊNCIAS}

AGUIAR, Vera T. de; BORDINI, Maria da Glória. Literatura - a formação do leitor: alternativas metodológicas. 2. ed. Porto Alegre: Mercado Aberto, 1988.

BAKHTIN, Mikhail. Estética da criação verbal. Trad. do francês por Maria Ermantina Galvão G. Pereira. 3. ed. São Paulo: Martins Fontes, 2003.

BAUMAN, Zigmunt. Sociedade líquida. Trad. Alexandre Wernek. São Paulo: Cortez, 2009.

CARRERA, Dolors (Coordinadora del Taller de Educación). Telematica y educación. In: Conclusiones del talles de educación - maio 1998, 1er. Congresso sobre publicación electrónica. Disponível em: <http://www.ucm.es/info/especulo/numero 8/dcarrera.html>. Acesso em: 10/06/2011.

CHAUÍ, Marilena. A universidade operacional, Folha de São Paulo, 1999. Disponível em: $<$ http://www1.folha.uol.com.br/fol/brasil500/dc_1_3.htm>. Acesso em: 20/03/2012.

CITELLI, Adilson (Coord.). Outras linguagens na escola: publicidade, cinema, tv, rádio, jogos, informática. São Paulo: Cortez, 2003.

EAGLETON, Terry. As ilusões do pós-modernismo. Rio de Janeiro: Jorge Zahar, 1998.

ECO, Umberto. Seis passeios pelo bosque da ficção. São Paulo: Cia. das Letras, 1994.

ISER, Wolfgang. The implied reader. Baltimore: The Johns Hopkins University Press, 1974. 
LIMA, Luiz Costa (Org. e Trad.). A literatura e o leitor. Rio de Janeiro: Paz e Terra, 1979.

MIALL, David. S. O momento hipertextual. Letras de hoje: estudos e debates de assuntos de linguística, literatura e língua portuguesa, v. 45, n. 2, 2010. Disponível em: <http:// revistaseletronicas.pucrs.br/ojs/index.php/fale/article/viewArticle/7523>. Acesso em: 23/09/2012.

PAZ, Octavio. Signos em rotação. 3. ed. Trad. Sebastião Uchoa Leite. São Paulo: Perspectiva, 1996.

SILVA, Maurício da. Repensando a leitura na escola: um outro mosaico. 3. ed. Niterói: EdUFF, 2002.

TEZZA, Cristóvão. Entre a prosa e a poesia: Bakhtin e o formalismo russo. Rio de Janeiro: Rocco, 2003.

TINOCO, Robson Coelho. Leitor real e teoria da recepção: travessias contemporâneas. Vinhedo, São Paulo: Horizonte; DEG/UnB, 2010.

Texto recebido em 25 de abril de 2014.

Texto aprovado em 07 de maio de 2014. 